International Braz J Urol

Vol. 35 (2): 217-226, March - April, 2009

\title{
Use of a Latex Biomembrane for Bladder Augmentation in a Rabbit model: Biocompatibility, Clinical and Histological Outcomes
}

\author{
Andre L. A. Domingos, Silvio Tucci Jr, Sergio B. Garcia, Jose de Bessa Jr, Adauto J. Cologna, \\ Antonio C. P. Martins \\ Department of Surgery, Division of Urology, Ribeirao Preto Medical School, University of Sao Paulo, \\ USP, Ribeirao Preto, SP, Brazil
}

\begin{abstract}
Purpose: To investigate histological features and biocompatibility of a latex biomembrane for bladder augmentation using a rabbit model.

Material and Methods: After a partial cystectomy, a patch of a non-vulcanized latex biomembrane $(2 \times 4 \mathrm{~cm})$ was sewn to the bladder with 5/0 monofilament polydioxanone sulfate in a watertight manner. Groups of 5 animals were sacrificed at 15, 45 and 90 days after surgery and the bladder was removed. The $5-\mu \mathrm{m}$ preparations obtained from grafted area and normal bladder were stained with hematoxylin-eosin. Immunohistochemical staining was performed with a primary antibody against alpha-actin to assess muscle regeneration.

Results: No death, urinary leakage or graft extrusion occurred in any group. All bladders showed a spherical shape. Macroscopically, after 90 days, the latex biomembrane was not identifiable and the patch was indistinguishable from normal bladder. A bladder stone was found in one animal (6.6\%). On the 90th day, histology revealed continuity of transitional epithelium of host bladder tissue on the patch area. At this time, the muscle layers were well organized in a similar fashion to native bladder muscle layers. The inflammatory process was higher on grafted areas when compared to controls: 15 days $-\mathrm{p}<0.0001,45$ days $-\mathrm{p}<0.001$, and 90 days $-\mathrm{p}<0.01$. The anti alpha-actin immunoexpression peaked at 45 days, when the graft was observed covered by muscle cells.

Conclusion: The latex biomembrane is biocompatible and can be used in models for bladder augmentation in rabbits. It promotes epithelium and muscle regeneration without urinary leakage.
\end{abstract}

Key words: bladder; latex; rabbit; smooth muscle; regeneration

Int Braz J Urol. 2009; 35: 217-26

\section{INTRODUCTION}

The worsening quality of life and the loss of upper urinary tract function are consequences of permanent reduction of bladder capacity and compliance, caused by neurogenic or non-neurogenic disorders. Bladder augmentation has the following objectives: reduction of intravesical pressure, improvement of urinary continence and preservation of upper urinary tract function (1). Gastrointestinal segments remains, even today, the most used technique for this purpose. Despite good functional results (2), bladder augmentation with intestinal segments presents disadvantages such as the production of mucus, electrolyte imbalance, development of intestinal and urinary fistula, bladder stones, spontaneous bladder perforation and carcinogenesis (1-3). Auto-augmentation and ureterocystoplasty has emerged as an alternative to override the complications caused by enterocystoplasties, but the first did not elicit long-term consistent results and 
the second, depends on the presence of a nonfunctioning kidney unit $(4,5)$.

As non-biodegradable synthetic material for bladder augmentation, such as silicon, polytetrafluoroethylene and polypropylene, has been unsuccessful, the development of biodegradable scaffolds seems to be more appropriate because it would allow the appropriate time to host tissue regeneration with dissolution before a foreign body reaction (6). In recent years, the porcine small intestinal submucosa (SIS) and the bladder acellular matrix graft (BAMG) have been used frequently in experimental studies. They act as biodegradable materials that allow the urothelial and smooth muscle regeneration $(7,8)$. However, the SIS and the BAMG are xenogeneic materials and require advanced technique preparation.

The natural latex biomembrane is extracted from the Hevea brasiliensis. Previous experimental studies have proved that the latex biomembrane is a biodegradable material with easy preparation and handling, encouraging tissue formation and angiogenesis $(9,10)$. No evidence of toxicity or allergenic reaction was found when the latex biomembrane was used to reconstruct the tympanic membrane in humans (11). However, the allergen potential of vulcanized latex is well established in latex glove users and other highrisk groups of patients with different latex exposure (12). This background prompted our interest in enlarging the bladder using this type of latex graft. The aim of the study was to investigate the clinical and histological features as well as the biocompatibility of a latex biomembrane for bladder augmentation in a rabbit model.

\section{MATERIALS AND METHODS}

A total of 15 adult male New Zealand rabbits weighing 3.0-3.4 Kg underwent bladder augmentation with the latex biomembrane. This project was approved by the Animal Research Committee of our Institution. Groups of five animals were sacrificed at 15 (group A), 45 (group B) and 90 (group C) days after grafting. As controls, in each rabbit we excised a bladder full thickness fragment distant from the grafted area.

\section{Membrane Preparation}

Matrix preparation followed the technique published previously (10). Briefly, the latex extracted from the Hevea brasiliensis tree was poured as a thin layer on Petri dishes and dried in an oven at $60^{\circ} \mathrm{C}$ for 20 minutes in order to promote the polymerization of latex's constituents. The latex membranes so obtained were immersed in a $0.1 \%$ solution of poly-L-lysine hydrobromide (MW 70-140 kD, Sigma) for 24h at room temperature. Then, the membranes were placed into a dry-heat oven at $60^{\circ} \mathrm{C}$ for 2 hours, packed and sterilized in ethylene oxide.

\section{Surgical Technique}

The animals were anesthetized by intramuscular injection of ketamine $(35 \mathrm{mg} / \mathrm{kg})$ and $\mathrm{xy}-$ lazin $(5 \mathrm{mg} / \mathrm{kg})$. A partial cystectomy $\left(4.0 \mathrm{~cm}^{2}-2.0\right.$ x $2.0 \mathrm{~cm})$, corresponding to nearly $15 \%$ of bladder size, was performed through a median laparotomy. A patch of $2.0 \times 2.0 \mathrm{~cm}$ of the latex biomembrane was grafted onto the remaining host bladder with a continuous suture of 5/0 monofilament absorbable polydioxanone sulfate. Four marking stitches of $5 / 0$ polypropylene were placed outside the bladder wall near the corners of the patch. Perivesical fat was fixed over the bladder wall to cover the graft.

\section{Follow-up}

Enrofloxacyn $(9 \mathrm{mg} / \mathrm{Kg})$ was given subcutaneous to all animals daily for 2 postoperative days. The clinical condition of all animals was evaluated daily from surgery until the sacrifice. The sacrifice was carried out with an intravenous injection of pentobarbital $(60 \mathrm{mg} / \mathrm{Kg})$. A macroscopic inspection was then performed before bladder removal. A silk ligature was placed around the urethra, samples for immunohistochemistry were taken and the bladder was filled in with $10 \%$ formalin and then immersed in the same solution.

\section{Histology and Immunohistochemistry}

Formalin fixed specimens from the grafted and control areas of the bladder were embedded in paraffin. Sections of $5 \mu \mathrm{m}$ were cut and stained with hematoxylin and eosin in order to evaluate the amount of inflammatory cells in the graft. 
For immunohistochemistry, samples from grafted and control areas were immediately fixed for $24 \mathrm{~h}$ in ice-cold $0.1 \mathrm{M} \mathrm{PBS}$, ph 7.4, containing 4\% paraformaldehyde, followed for cryoprotection in $15 \%$ of sucrose for $4 \mathrm{~h}$ and $30 \%$ sucrose overnight at $4{ }^{\circ} \mathrm{C}$. Longitudinal sections $(3 \mu \mathrm{m})$ of samples were incubated with $3 \% \mathrm{H} 2 \mathrm{O} 2$ and Pierce solution to block endogenous peroxidase and biotin, respectively. Sections were subsequently incubated with primary antibodies against anti-smooth muscle alpha-actin (1:80 dilution, clone RBC2/1B6, Novocastra $\left.{ }^{\circledR}\right)$ and with biotin-conjugated secondary anti-rabbit antibody $(1: 1000$; Vector Laboratories Inc., Burlingame, USA) and streptavidin-conjugated peroxidase (Vecstatin Abc kit, Vector Laboratories Inc.). Color was developed by the addition of DAB (Sigma Chemical, St. Louis, USA). To evaluate the background reaction, procedures were also performed in sections incubated only with the secondary antibodies (indirect technique) or in the absence of antibodies (direct technique). The number of cell with positive staining for alphaactin was estimated by using a camera (Axio Cam, Zeiss, Germany) and the program Axiovision 4.6 (Zeiss, Germany).

In histological / immunohistochemical evaluation, 10 microscope fields were examined. Cells were counted at a 400X magnification by two different pathologists in a blind manner. The semi-quantitative analysis was determined and expressed as a percentage of inflammatory cells and cells labeled with anti-smooth muscle alphaactin, as follows: Score 0: 0-5\%, Score I: $5-25 \%$, Score II: $25-50 \%$, Score III: $50-75 \%$ and Score IV: $>75 \%$.

\section{Statistical Analysis}

Data are provided as medians and range. The comparisons between the treated and controls areas were analyzed by the Wilcoxon test. The relationships between groups were analyzed with analysis of variance (Kruskal-Wallis test), followed by the Dunn's test to compare individual pairings. Statistical analysis was performed using the GraphPad Prism 4.03 program (San Diego, CA, USA) and $p$ values $<0.05$ were considered statistically significant.

\section{RESULTS}

\section{Macroscopic Evaluation}

All rabbits were able to void spontaneously after the operation and no animal exhibited urinary leakage. All bladders had a spherical shape.

On the 15th postoperative day, blood vessels were visible around the grafted area. After a longitudinal incision of the bladder, the presence of the latex matrix was easily identified since it was almost intact.

On the 45th day after surgery, the graft was almost entirely integrated to the host tissue of the native bladder. Bladder wall was thicker, mainly around the latex membrane. One bladder stone $(1.5 \times 2.0 \mathrm{~cm})$ was observed in one rabbit $(6.6 \%)$.

After 90 days from surgery, there was a decrease on bladder wall hypertrophy and the graft was indistinguishable from the normal host bladder at inner and outer surfaces. There was blood vessel reduction around the grafted area (Figure-1).

\section{Microscopic Evaluation}

On the 15th postoperative day, the luminal surface of the latex matrix was still uncovered by the urothelium. Fibrovascular reaction was present, with rare fibroblasts and a moderate amount of inflammatory cells, mainly macrophages. Forty-five days after surgery there was a diffuse epithelial and smooth muscle hyperplasia on the graft. At 90 days, there was a reduction on epithelial and muscle hyperplasia, and the urothelium was similar to the native bladder (Figure-2). At this time, the smooth muscle layers were well organized and in a similar direction in comparison to native bladder muscle layers.

\section{Inflammatory Response}

Significant inflammatory cells were not observed in the controls (score 0 ). The inflammatory process was higher 15 days after the procedure and decreased gradually from the time of grafting, tending to normalization at 90 days. This occurred despite the significant difference between grafted and non-grafted areas in all groups (Table-1).

The neutrophils and mononuclear cells were the main component of the widespread inflammatory process in the patch from group A, but inflammation 

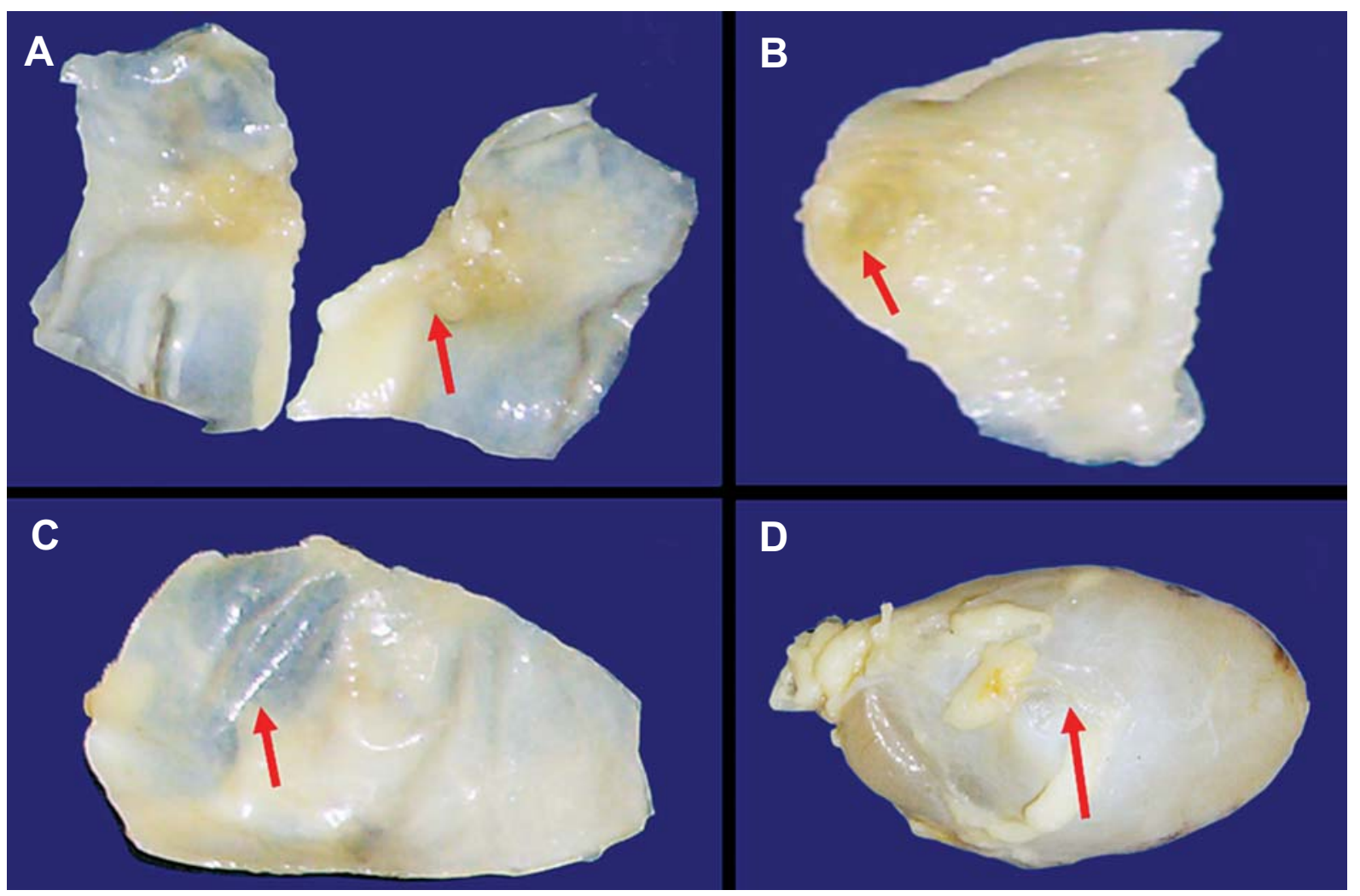

Figure 1 - Macroscopic evaluation of the latex biomembrane. A) Presence of the membrane 15 days after surgery. B) Thick bladder wall at 45 days. C) and D) Incorporation of the latex membrane (interior) and spherical architecture (exterior) after 3 months.

decreased with the time of follow-up being restricted around the remaining latex membrane in group $\mathrm{C}$ (Figure-3).

\section{Smooth Muscle Layer Regeneration}

The infiltration of alpha-actin-positive cells started from the border toward the center of the graft. During the first 15 days (Group A), the bladder smooth cell regeneration had began poorly and did not exhibit spatial organization, mainly near the anastomosis area. The expression of alpha-actin positive cells peaked at 45 days (Group B) after surgery, and then, slowly decreased. By the 90th post-surgical day (Group C), the smooth muscle cells were well developed and oriented, however it was difficult to distinguish the junction between the graft area and host bladder muscle (Figure-4).

The expression of the alpha-actin varied significantly according to the time elapsed $(\mathrm{p}=0.001)$
(Kruskal-Wallis' test). Higher expression was detected in grafted area in animals from group B (45th day) that was statistically different in comparison with groups A (15th day) and $C$ (90th day) $(\mathrm{p}=0.001)$. When compared to controls the expression was significantly higher in groups $\mathrm{B}$ and $\mathrm{C}$ and was similar in group $\mathrm{A}$. (Wilcoxon paired test). There was no change in the expression of alpha-actin in non-grafted areas with time (Table-1).

\section{COMMENTS}

The ideal material for bladder augmentation should allow the progressive growth of all components of the normal bladder wall, preserving their mechanical and functional properties $(7,8,13)$. Probst et al. (8) showed that bladder augmentation in rats with BAMG is associated with a high mortality rate 


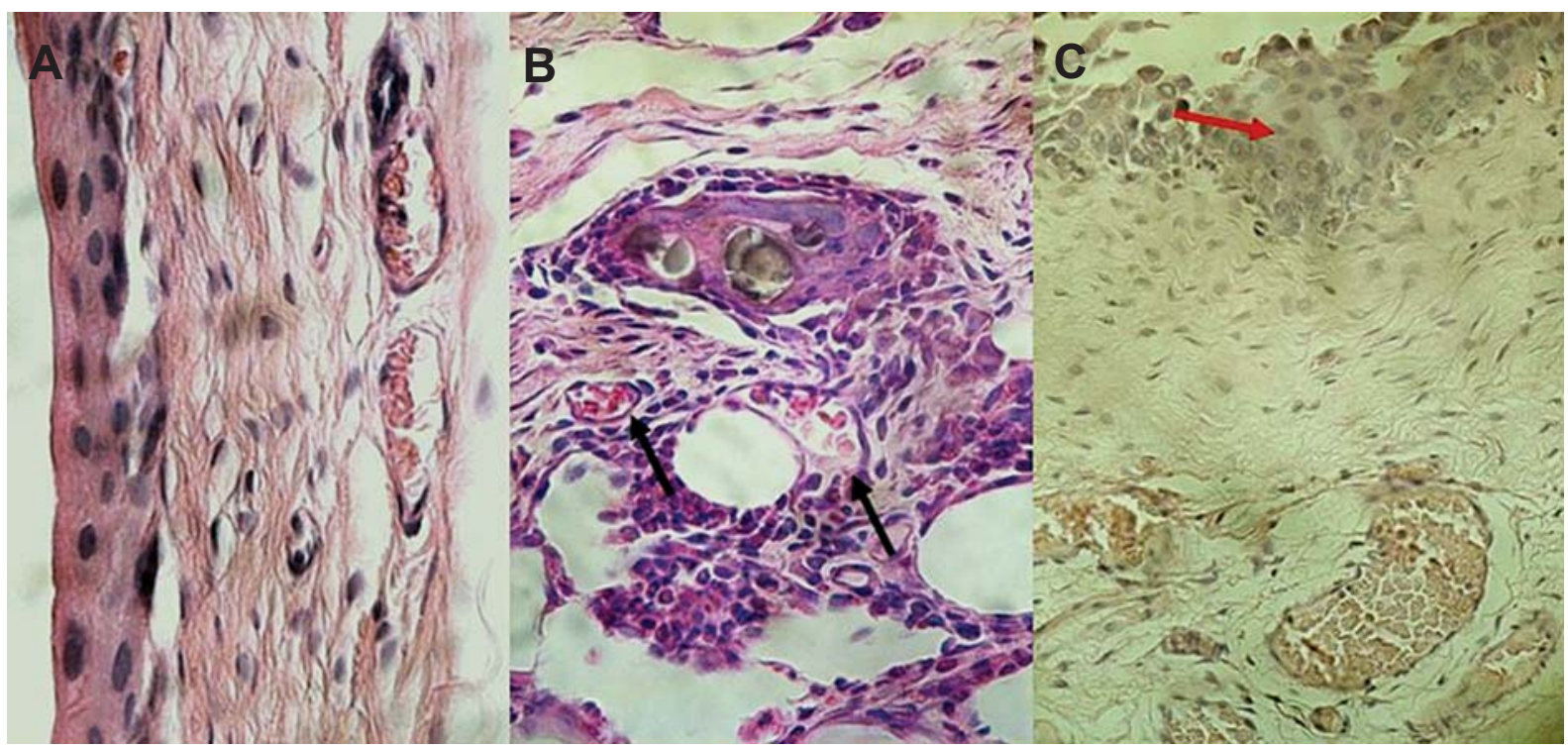

Figure 2 - A) Non-grafted area (controls). B) Blood vessels 15 days after grafting (black arrows). C) Urothelial layer 90 days after surgery (red arrow). HE, X400.

$(32 \%)$ due to urinary leakage and/or bladder neck obstruction. However, in the surviving rats, the graft was progressively infiltrated by vessels and smooth muscle cells of the host and the mucosal lining was complete within 10 days. The ingrowth was complete after 8 weeks, except for neural regeneration, which was only partial. At 12 weeks, the bladder wall muscle structure in the graft was so well developed that it was difficult to delineate the junction between host bladder and BAMG. These authors concluded that BAMG appears to serve as a framework of collagen and elastin for the ingrowths of all bladder wall components. The high mortality rate caused by urinary leakage in the model of bladder augmentation in rats with BAMG has also been reported elsewhere (13). Ayyildiz et al. (7) reported that SIS seems to be a viable alternative to the use of intestine in bladder augmentation in rabbits since at the end of 12 months, the long-term

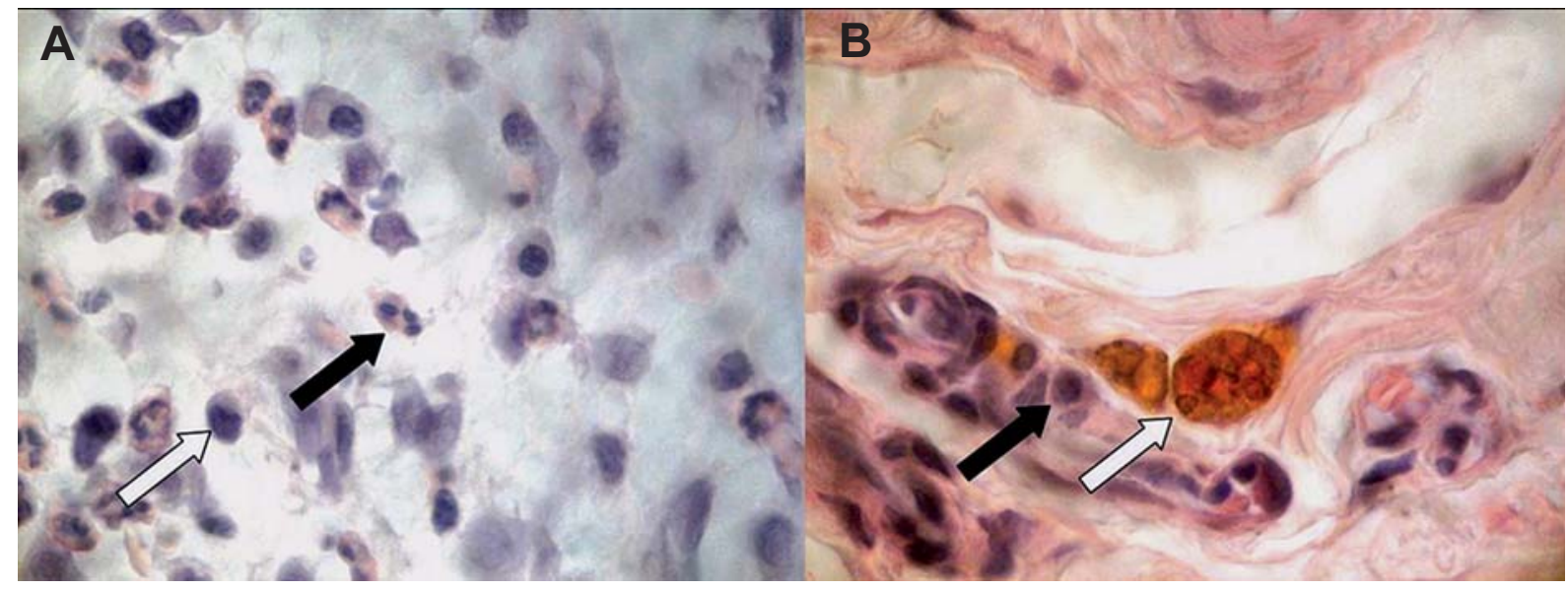

Figure 3-A) Inflammatory cells in the grafted area 15 days after surgery - neutrophil (black arrow) and mononuclear leukocyte (white arrow). B) Inflammatory response - lymphocytes (black arrow) around the remaining latex membrane (white arrow) after 90 days. 

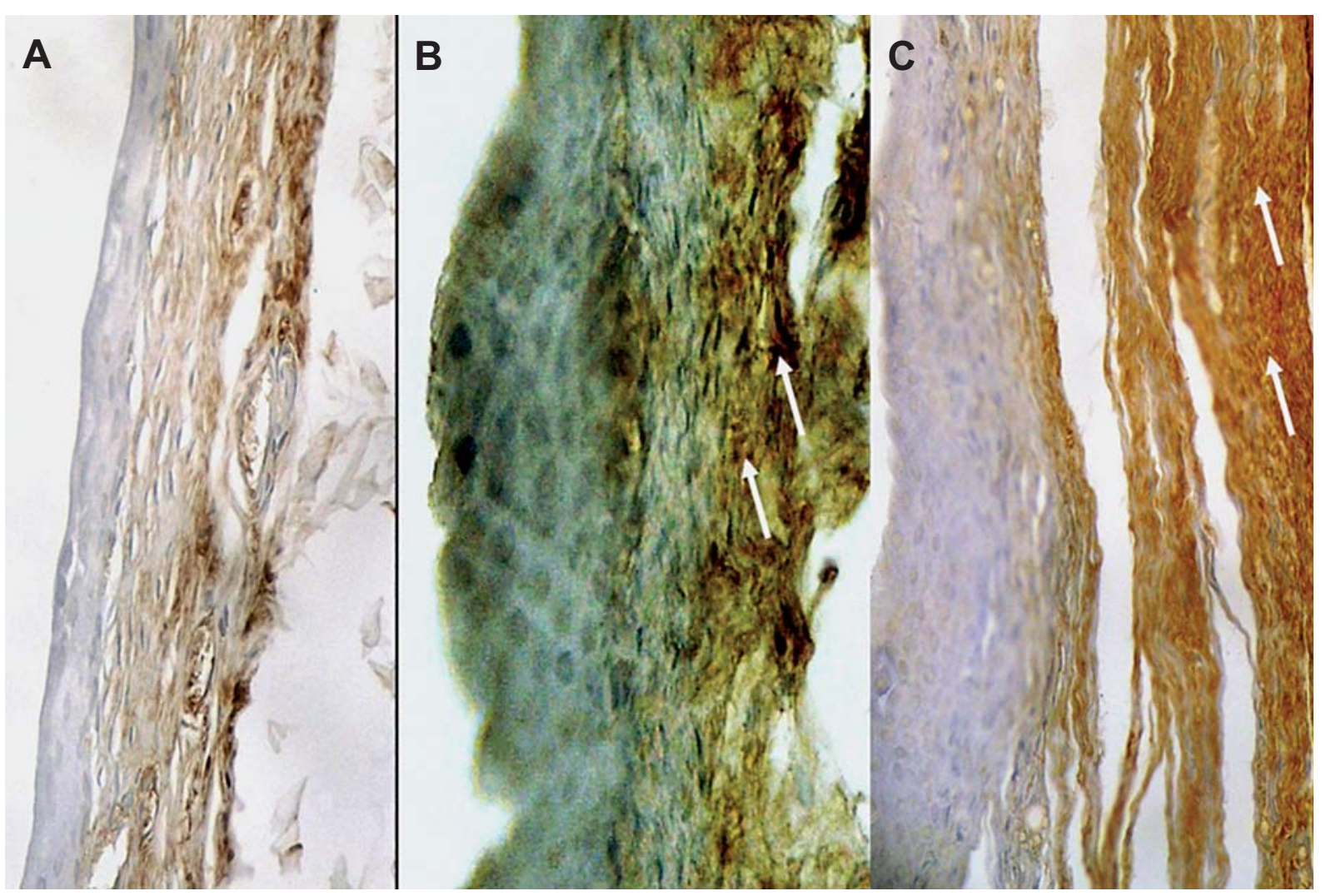

Figure 4-Changes in alpha-actin expression over time. A) Muscle layer of non-grafted area. B) Hyperplasia of smooth muscle cells growing into the latex biomembrane 45 days after surgery; note the high expression of alpha-actin (stained in brown - white arrows). C) Reduction of alpha-actin-positive expression and muscular cells with a lesser degree of hyperplasia 3 months after surgery.

Table 1 - Inflammatory response and alpha-actin immunoexpression according to the groups at different times of evaluation. Data expressed as medians and ranges.

\begin{tabular}{lccc}
\hline & Control & Experimental & p Value * \\
\hline Inflammatory Response & & & \\
15th day & 0 & $3(3-4)$ & $<0.0001$ \\
45th day & 0 & $2(1-2)$ & $<0.001$ \\
90th day & 0 & $1(1-2)$ & \\
Alpha-actin & & & $\mathrm{ns}$ \\
15th day & 1 & $1(1-2)$ & $<0.001$ \\
45th day & 1 & $3(2-3)$ & 0.02 \\
90th day & 1 & $2(1-2)$ & \\
\hline
\end{tabular}

Numbers represent score; $*$ Wilcoxon paired test; $n s=$ not significant.

histological features of bladder augmentation was indistinguishable from original bladder. The rabbit model is suitable for bladder tissue engineering studies, but blad- der augmentation with SIS or collagen-based biomatrix exhibits a high rate $(37 \%)$ of stone formation and/or encrustation of foreign body material (14). 
Our data show for the first time that latex biomembrane used for bladder augmentation in rabbits allows a progressive ingrowth of all components of the normal bladder wall without postoperative urinary leakage and a low rate of stone formation. After 3 months, the smooth muscle cells were well developed and oriented, and were difficult to delineate the junction between the grafted area and host bladder muscle. It also seems that this biodegradable material offers the advantage to reduce the rate of stone formation or encrustation (6.6\%) in comparison with SIS, collagen-based biomatrix and bowel segments.

The inflammatory process in bladder augmentation with collagen-based biomatrix may be secondary to early congestion of the grafts as well as to stimuli caused by the graft components (15). This reaction was stronger in the first 2 weeks following the surgery, but thereafter its intensity reduces progressively. The inflammatory process must be temporary and not lead to graft rejection (8). The vigorous inflammatory response caused by grafted extracellular matrix is restrict to a $\mathrm{TH} 2$ lymphocytes immune response, which results in tissue remodeling rather than tissue destruction or rejection (16). Our data with latex biomembrane showed that the inflammatory reaction was more intense on the 15th postoperative day and decreased significantly later on, which may be regarded as an evidence of no rejection. Previous reports on production of inflammation cytokines induced by latex biomembrane in vitro showed enhancement of production of interleukin-10 and reduction of interferon $\mathrm{Y}$, which suggest that such material elicits an immune response restricted to $\mathrm{TH} 2 \mathrm{lym}-$ phocytes (17). It is relevant to stress that during latex biomembrane preparation, one must preserve the native conformation of latex proteins by avoiding temperatures higher than $60^{\circ} \mathrm{C}$ and hence the latex vulcanization, otherwise the inflammatory response changes from a tissue repair type toward a rejection type, as shown previously by electron microscopy $(9,18)$.

The exact origin of smooth muscle cells (SMC) in the bladder grafts remains unclear. Some authors suggest a major role for pluripotential stem cells in the graft cellular regeneration $(19,20)$. On the other hand, other authors have demonstrated that muscle layer regeneration occurs by migration of dedifferentiated bladder SMC from the matrixbladder junction (15). Previous experimental studies with the latex biomembrane have shown that it allows the ingrowths of epithelial, submucosal glands and muscular cells of canine esophagus (9). The results of our study suggest that the muscle layer regeneration occurs from the host bladder since alpha-actin was first observed in this area. Bladder augmentation with other extracellular matrix graft showed that the expression of alpha-actin was first visualized on day 4 after the procedure, peaked at day 10 and then decreased. Expression increased again gradually after 3 to 4 weeks and progressed for 12 weeks (14). The early peak of alpha-actin expression was interpreted most likely as a consequence of artifacts caused by the higher number of cells in the matrix rather than the real expression of muscle cells in the matrix. Other studies showed a progressive expression of alpha-actin from $15 \%$ in the first 2 weeks to $36 \%$ in the 12th week, at a time when muscle layer was well developed and oriented (8). The current study demonstrated that the alpha-actin expression was higher 45 days after surgery and decreased thereafter. At the end of the experiment, muscle layer was well organized, similar to the host tissue. These findings support the idea that latex biomembrane can be used as a matrix in experimental studies of bladder augmentation because it is well tolerated and promotes adequate smooth muscle regeneration.

\section{CONCLUSION}

This study demonstrates the biocompatibility of the latex biomembrane as a matrix for bladder augmentation in rabbits. The matrix promotes epithelium and muscle regeneration without urinary leakage. More detailed investigations on its functional properties are warranted in the future.

\section{CONFLICT OF INTEREST}

None declared. 


\section{REFERENCES}

1. Greenwell TJ, Venn SN, Mundy AR: Augmentation cystoplasty. BJU Int. 2001; 88: 511-25.

2. Blaivas JG, Weiss JP, Desai P, Flisser AJ, Stember DS, Stahl PJ: Long-term followup of augmentation enterocystoplasty and continent diversion in patients with benign disease. J Urol. 2005; 173: 1631-4.

3. Gilbert SM, Hensle TW: Metabolic consequences and long-term complications of enterocystoplasty in children: a review. J Urol. 2005; 173: 1080-6.

4. Lindley RM, Mackinnon AE, Shipstone D, Tophill PR: Long-term outcome in bladder detrusorectomy augmentation. Eur J Pediatr Surg. 2003; 13 (Suppl 1): $\mathrm{S} 7-12$.

5. Landau EH, Jayanthi VR, Khoury AE, Churchill BM, Gilmour RF, Steckler RE, et al.: Bladder augmentation: ureterocystoplasty versus ileocystoplasty. J Urol. 1994; 152: 716-9.

6. Atala, A: Tissue engineering in the genitourinary system, pp. 149-164, in Tissue Engineering, Atala A., Mooney, D. (eds). Birkhauser Press, Boston, MA, 1997.

7. Ayyildiz A, Akgül KT, Huri E, Nuhoglu B, Kiliçoglu B, Ustün $\mathrm{H}$, et al.: Use of porcine small intestinal submucosa in bladder augmentation in rabbit: longterm histological outcome. ANZ J Surg. 2008; 78: 82-6.

8. Probst M, Dahiya R, Carrier S, Tanagho EA: Reproduction of functional smooth muscle tissue and partial bladder replacement. Br J Urol. 1997; 79: 505-15.

9. Mrue F: Tissue Neoformation Induced by Natural Latex Biomembrane with Polylysine: Application in Esophagus and Abdominal Wall Neoformation in Dogs. Ph.D. Thesis. Ribeirão Preto School of Medicine, University of São Paulo, 2000. 112 p. [in Portuguese]

10. Brandão ML, Coutinho-Netto J, Thomazini JÁ, Lachat JJ, Muglia VF, Piccinato CE: Prótese vascular derivada do látex. J Vasc Brás. 2007; 6: 130-41.

11. Oliveira JA, Hyppolito MA, Coutinho-Netto J, Mrué F: Miringoplastia com a utilização de um novo material biossintético. Rev Bras Otorrinolarigol. 2003; 69: 649-55.

12. Rolland JM, O'Hehir RE: Latex allergy: a model for therapy. Clin Exp Allergy. 2008; 38: 898-912.

13. Wefer J, Sievert KD, Schlote N, Wefer AE, Nunes L, Dahiya R, et al.: Time dependent smooth muscle regeneration and maturation in a bladder acellular matrix graft: histological studies and in vivo functional evaluation. J Urol. 2001; 165: 1755-9.
14. Nuininga JE, van Moerkerk $H$, Hanssen A, Hulsbergen CA, Oosterwijk-Wakka J, Oosterwijk E, et al.: A rabbit model to tissue engineer the bladder. Biomaterials. 2004; 25: 1657-61.

15. Kajbafzadeh AM, Payabvash S, Salmasi AH, Sadeghi Z, Elmi A, Vejdani K, et al.: Time-dependent neovasculogenesis and regeneration of different bladder wall components in the bladder acellular matrix graft in rats. J Surg Res. 2007; 139: 189-202.

16. Allman AJ, McPherson TB, Badylak SF, Merrill LC, Kallakury B, Sheehan C, et al.: Xenogeneic extracellular matrix grafts elicit a TH2-restricted immune response. Transplantation. 2001; 71: 1631-40.

17. Lamounier F: In Vitro Evaluation of Inflammatory Cytokines Production Induced by Natural Latex Biomembrane from Rubber Plant Hevea brasiliensis. MS Thesis. Ribeirão Preto School of Medicine, University of São Paulo, 2004. 115 p. [in Portuguese]

18. Andrade TA: Activity of Natural Latex Biomembrane from Rubber Plant Hevea brasiliensis in Tissue Neoformation in Mice. MS Thesis. Ribeirão Preto School of Medicine, University of São Paulo, 2007. 138 p. [in Portuguese]

19. Kanematsu A, Yamamoto S, Iwai-Kanai E, Kanatani I, Imamura M, Adam RM, et al.: Induction of smooth muscle cell-like phenotype in marrow-derived cells among regenerating urinary bladder smooth muscle cells. Am J Pathol. 2005; 166: 565-73.

20. Frid MG, Kale VA, Stenmark KR: Mature vascular endothelium can give rise to smooth muscle cells via endothelial-mesenchymal transdifferentiation: in vitro analysis. Circ Res. 2002; 90: 1189-96.

Accepted after revision:

January 21, 2009

\section{Correspondence address:}

Dr. André Luís A. Domingos

Rua Padre João Cripa, 780, Centro

Campo Grande, MS, 79002-380, Brazil

Fax: + 5567 3325-7488

E-mail: andre@urovida.com.br 


\section{EDITORIAL COMMENT}

I have read an interesting paper entitled, "Use of a Latex biomembrane to bladder augmentation in rabbits: biocompatibility, clinical and histological outcomes" prepared by Dr. Domingos and colleagues. Bladder tissue engineering is a developing field of regenerative medicine regardless the objective difficulties of in vitro creation of functional bladder wall. Bladder wall regeneration by means of tissue engineering techniques depends on several factors, i.e.: cells, proper scaffold, nutrition and stimulus supply within the host organism. This paper is dedicated to scaffold. The optimal conditions for the proliferation of bladder cells, their terminal differentiation and influence on neo-tissue remodeling were shown to be a desired behavior of both transplanted and host cells. A good scaffold can help to achieve this difficult task, by promotion of mentioned above processes. It was proved that even decellularized animal or human scaffolds were not ideal. The deposition of dense connective tissue and scarring are often observed during healing of tissue-engineered bladder wall. The failure of regeneration can be evoked by allo- or xenogenic cellular remnants within the biological scaffold, urine leakage, etc. Poorly compliant bladder is a result of these unwanted events. Bladder regeneration is much more complicated in a disease condition. The most current experimental works are performed on healthy bladders. There is still a need to create a low immunogenic, high adhesive and biocompatible scaffold for bladder tissue engineering. Dr. Domingos and colleagues are working in this field. They show that even latex can be prepared in such way to be atoxic to bladder cells and promoted in vivo regeneration. They presented bladder wall regeneration induced by latex modified biomaterial within the animal model. It should be emphasized that scaffold has to be a biological niche for differentiated cells and their stem (undifferentiated) counterparts during in vivo regeneration. It seems that the role of scaffold during the regeneration process is equal to cellular compartment, so I have found this work important. This paper is a very good "background" for the future experiments with the cell-seeded matrices performed on healthy and disease affected bladders.

\section{Dr. Tomasz Drewa Department of Urology Department of Tissue Engineering Nicolaus Copernicus University Bydgoszcz, Poland E-mail: tomaszdrewa@wp.pl}

\section{EDITORIAL COMMENT}

Many different materials have been investigated for use as scaffolds in tissue engineering. In bladder augmentation models these materials have included collagen, synthetic polyesters such as polyglycolic acid, bladder acellular matrix grafts, and porcine small intestine submucosa. The authors present their initial histological findings using a latex biomembrane scaffold for bladder augmentation in rabbits. Multiple groups from the University of Sao Paulo have shown that the latex biomembrane allows healing in the esophagus (1), the mastoid and dental alveolar bones $(2,3)$ and ulcerated skin (4). In this manuscript, the authors similarly observed progressive smooth muscle growth at the bladder graft site and concluded that further functional studies of the latex biomembrane in the bladder are warranted.

Several concerns will need to be addressed in order to determine if the latex biomembrane bladder augmentation is applicable to human patients. Prior in vitro studies have shown than latex is more 


\section{Latex Biomembrane for Bladder Augmentation in Rabbits}

cytotoxic to cultured bladder smooth muscle cells compared to other traditional biomaterials (4). More importantly, a large percentage of patients requiring bladder augmentation are children with spina bifida who have a high risk of latex allergy. Nonetheless, the authors should be commended for their initial work using a novel scaffolding material in bladder augmentation.

\section{REFERENCES}

1. Alves de Sousa LC, Ribeiro de Toledo Piza M, Coutinho-Netto J, Ruiz DB, Schmidt VB: Latex biomembrane: a new method to coat the open cavity in tympanomastoidectomies. Braz J Otorhinolaryngol. 2007; 73: 331-6.
2. Balabanian CA, Coutinho-Netto J, Lamano-Carvalho TL, Lacerda SA, Brentegani LG: Biocompatibility of natural latex implanted into dental alveolus of rats. $\mathrm{J}$ Oral Sci. 2006; 48: 201-5.

3. Frade MA, Valverde RV, de Assis RV, Coutinho-Netto J, Foss NT: Chronic phlebopathic cutaneous ulcer: a therapeutic proposal. Int J Dermatol. 2001; 40: 23840.

4. Pariente JL, Kim BS, Atala A: In vitro biocompatibility evaluation of naturally derived and synthetic biomaterials using normal human bladder smooth muscle cells. J Urol. 2002; 167: 1867-71.

Dr. Stacy T. Tanaka

Division of Pediatric Urology

Monroe Carell Jr. Children's Hospital at Vanderbilt

Nashville, Tennessee, USA

E-mail: stacy.tanaka@vanderbilt.edu 